See discussions, stats, and author profiles for this publication at: https://www.researchgate.net/publication/349815680

\title{
Healthy herds in the phytoplankton: the benefit of selective parasitism
}

Article in The ISME Journal · March 2021

DOI: 10.1038/541396-021-00936-8

\section{CITATIONS}

0

4 authors, including:

$$
\text { Davis Laundon }
$$

Marine Biological Association of the UK

10 PUBLICATIONS 57 CITATIONS

SEE PROFILE

Glen Wheeler

Marine Biological Association of the UK

109 PUBLICATIONS 6,422 CITATIONS

SEE PROFILE

\section{READS}

114

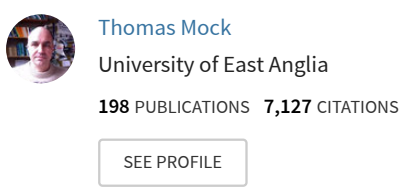

Some of the authors of this publication are also working on these related projects:

Evolutionary genomics of the diatom Skeletonema marinoi View project

Building a locally diploid genome and transcriptome of the diatom Fragilariopsis cylindrus View project 


\title{
Healthy herds in the phytoplankton: the benefit of selective parasitism
}

\author{
Davis Laundon ${ }^{1,2} \cdot$ Thomas Mock $\mathbb{1}^{2} \cdot$ Glen Wheeler ${ }^{1} \cdot$ Michael Cunliffe $\mathbb{C}^{1,3}$
}

Received: 27 October 2020 / Revised: 8 February 2021 / Accepted: 10 February 2021

(c) The Author(s), under exclusive licence to International Society for Microbial Ecology 2021

\begin{abstract}
The impact of selective predation of weaker individuals on the general health of prey populations is well-established in animal ecology. Analogous processes have not been considered at microbial scales despite the ubiquity of microbe-microbe interactions, such as parasitism. Here we present insights into the biotic interactions between a widespread marine thraustochytrid and a diatom from the ecologically important genus Chaetoceros. Physiological experiments show the thraustochytrid targets senescent diatom cells in a similar way to selective animal predation on weaker prey individuals. This physiology-selective targeting of 'unhealthy' cells appears to improve the overall health (i.e., increased photosynthetic quantum yield) of the diatom population without impacting density, providing support for 'healthy herd' dynamics in a protist-protist interaction, a phenomenon typically associated with animal predators and their prey. Thus, our study suggests caution against the assumption that protist-protist parasitism is always detrimental to the host population and highlights the complexity of microbial interactions.
\end{abstract}

Animal predators can exert overall positive effects on the health of prey populations by removing individuals with suboptimal health $[1,2]$ in a manner that has been termed 'healthy herd' dynamics [3]. While such top-down processes are well-established in animal ecology [1-3], they have largely been unconsidered in microbe-microbe interactions.

Protist-protist parasitism is widespread in the marine environment [4] and is generally considered to be detrimental to host populations [5, 6]. However, despite their ubiquity, the ecophysiological impact of protist-protist parasitism remains poorly understood. An important case

Supplementary information The online version contains supplementary material available at https://doi.org/10.1038/s41396021-00936-8.

Michael Cunliffe

micnli@mba.ac.uk

1 Marine Biological Association of the UK, The Laboratory, Citadel Hill, Plymouth, UK

2 School of Environmental Sciences, University of East Anglia, Norwich, UK

3 School of Biological and Marine Sciences, University of Plymouth, Plymouth, UK that necessitates investigation is protist parasitism of diatoms, which have limited representation with culturedependent model systems despite the significance of diatoms in marine ecosystem functioning and global primary production [7].

We observed and isolated a heterotrophic protist growing epibiotically on moribund and dead Chaetoceros sp. diatoms from a summer bloom at Station L4 in the Western English Channel off Plymouth (UK) (Fig. 1A, B; Supplementary Figs. 1 and 2; Supplementary Methods). Single-cell picking achieved diatom and parasite co-cultures and uninfected host diatoms. The $18 \mathrm{~S}$ rRNA gene $\mathrm{V} 4$ region of the protist (termed 'ThrauL4') identified the epibiont as a novel thraustochytrid (Stramenopila; Labyrinthulomycota; Thraustochytrida) (Supplementary Fig. 3). Searching for ThrauL4 $18 \mathrm{~S}$ rRNA gene homologues in the Ocean Sampling Day dataset revealed that the parasite has a wide distribution in coastal temperate regions (Supplementary Fig. 4).

Stable Chaetoceros-ThrauL4 co-cultures permitted the characterisation of ThrauL4 internal structures (Supplementary Figs. 5 and 6), epibiotic growth (Fig. 1A, B; Supplementary Figs. 7 and 8) and infection dynamics (Fig. 1C, D). ThrauL4 also attached to other diatoms (Odontella sinensis, Ditylum brightwellii and Coscindodiscus sp.) in a similar manner to Chaetoceros sp. but not dinoflagellates (Fig. 1C; Supplementary Fig. 9). 

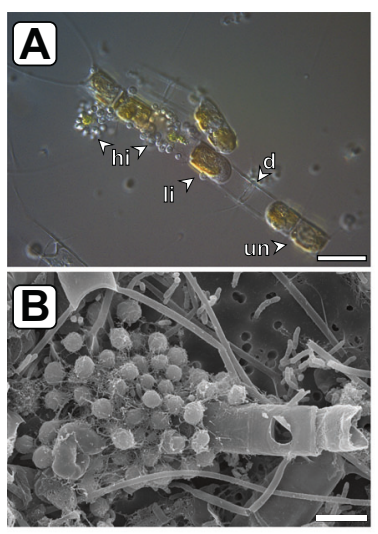

H

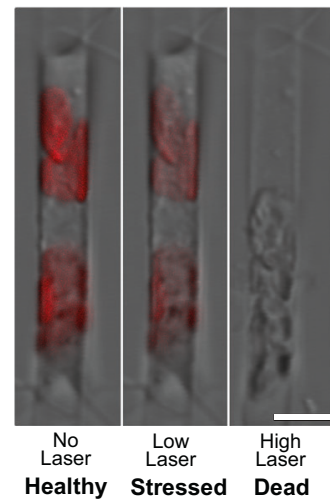

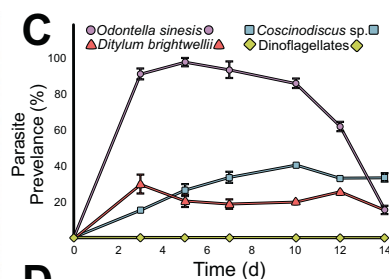
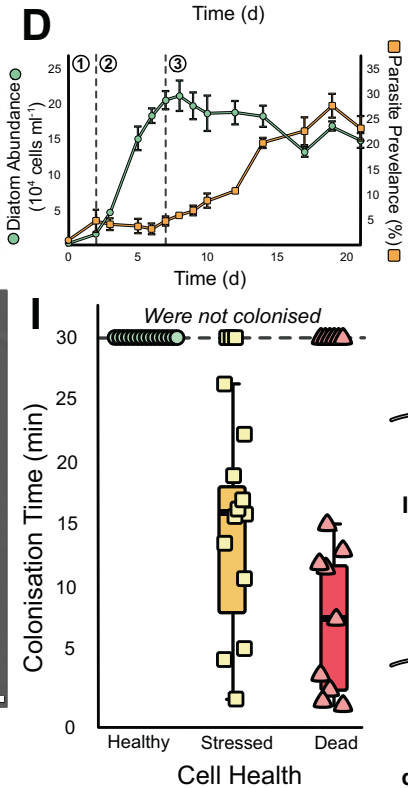

E
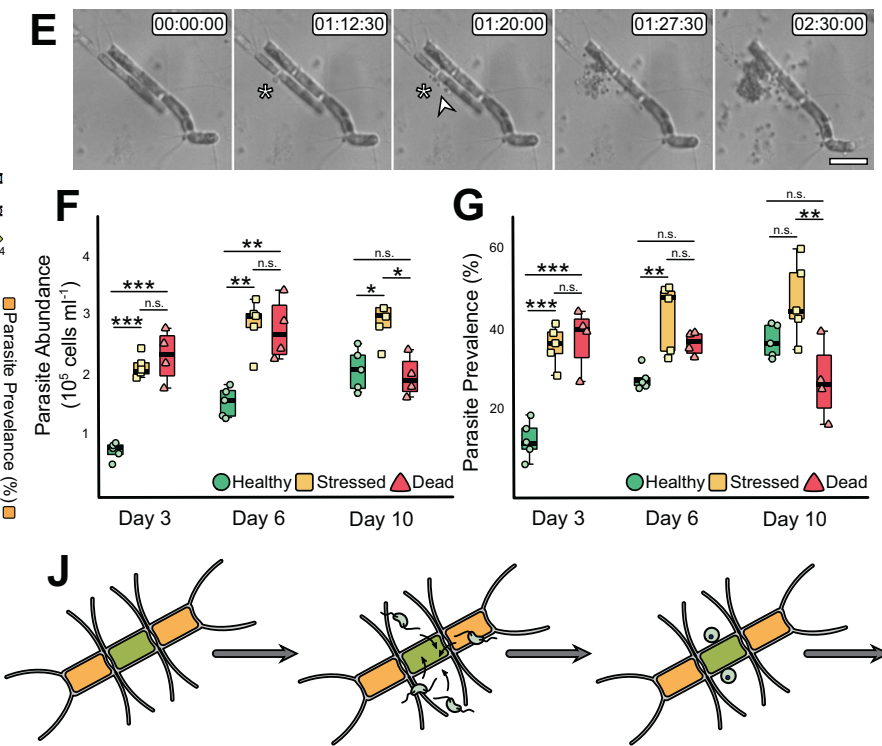
$\begin{array}{cc}\text { Individual diatom cells } & \text { Zoospores target } \\ \text { become unhealthy } & \text { unhealthy diatom cells }\end{array}$

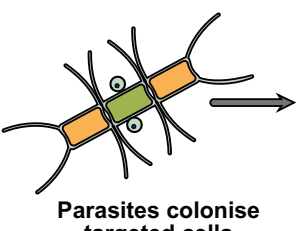
targeted cells

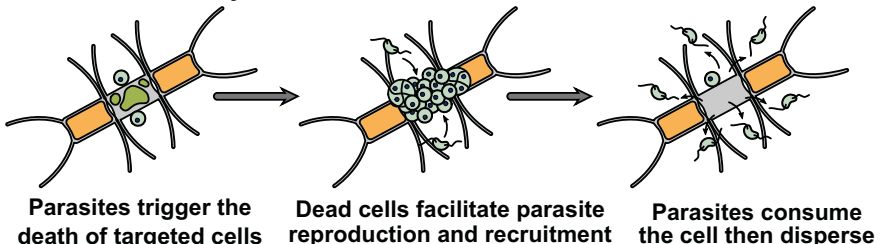

$\begin{array}{ccc}\text { Parasites trigger the } & \text { Dead cells facilitate parasite } \\ \text { death of targeted cells } & \begin{array}{c}\text { Parasites consume } \\ \text { reproduction and recruitment }\end{array} \text { the cell then disperse }\end{array}$
Fig. 1 Growth experiments demonstrate that thraustochytrids preferentially target and grow on unhealthy diatom cells. A Differential interference contrast (DIC) image of Chaetoceros chain exhibiting different degrees of infection by ThrauL4. Uninfected cell (un), a lightly infected cell (li), heavily infected cells (hi) and a dead, empty frustule (d). Scale bar $=20 \mu \mathrm{m}$. B Scanning Electron Micrograph (SEM) of a Chaetoceros diatom swarmed by ThrauL4. Scale bar $=5 \mu \mathrm{m}$. C ThrauL4 growth dynamics on a selected range of diatoms and dinoflagellates (Alexandrium minutum and Prorocentrum minimum) ( \pm SEM, $n=3)$. D Chaetoceros growth with ThrauL4 ( \pm SEM, $n=5)$. Dashed lines demarcate the lag (1), exponential (2) and stationary (3) phases of Chaetoceros growth. E Time-lapse of Chaetoceros-ThrauL4 showing ThrauL4 colonising unhealthy cells. Asterisk $=$ cytoplasmic bleb from

The proportion of diatom cells with ThrauL4 attached increased when Chaetoceros sp. cells entered the stationary growth phase (Fig. 1D). Time-lapse microscopy revealed the dynamic nature of the ThrauL4-diatom interaction (Fig. 1E, Supplementary Movies 1-6), with the motile ThrauL4 apparently targeting physiologically 'unhealthy' cells identified by cytoplasmic blebbing prior to colonisation (Fig. 1E).

We set out to test the hypothesis that ThrauL4 targeted unhealthy diatoms using population-level ecophysiology experiments. When introduced to heat-stressed diatom populations, ThrauL4 had a higher fitness (i.e. became more abundant) and infected more Chaetoceros sp. cells than when exposed to healthy un-stressed diatoms (Fig. 1F, G), confirming more optimal growth of the parasite amongst unhealthy diatom populations. Furthermore, selective unhealthy diatom. Arrowhead $=$ initial thraustochytrid colonisation. Timestamp $=$ HH:MM:SS. Difference in the abundance $(\mathbf{F})$ and prevalence $(\mathbf{G})$ of parasites in healthy (control), stressed and dead Chaetoceros populations $(n=5)$ inoculated with ThrauL4 following heat stress exposure. ANOVA Tukey's HSD n.s $p>0.05$ (not significant), ${ }^{*} p$ $<0.05, * * p<0.01, * * * p<0.001$. H Example diatom exposed to different laser powers used to generate individual Chaetoceros cells of varying health. Red channel overlay demarks chlorophyll autofluorescence. Scale bar $=5 \mu \mathrm{m}$. I Time taken for individual diatom cells $(n=15)$ exposed to varying laser treatments to be colonised by ThrauL4. J Diagrammatic representation of the proposed diatom-thraustochytrid interaction cycle based on time-lapse microscopy observations (see Supplementary Videos).

targeting was also demonstrated at the single-cell level using laser-damaged individual cells and time-lapse microscopy (Fig. 1H, I). $80 \%$ of stressed cells and $60 \%$ of dead cells were colonised by ThrauL4 during the $30 \mathrm{~min}$ experimental period, whereas diatoms in healthy control populations were un-colonised.

These results led us to investigate the physiological impact of thraustochytrid parasitism on host diatom populations by comparing the dynamics and health of parasite exposed and non-exposed Chaetoceros sp. populations (Fig. 2A-C). Based on the previous growth experiments showing ThrauL4 proliferation during the diatom stationary phase (Fig. 1D), Chaetoceros sp. cultures grown to their stationary phase after $7 \mathrm{~d}$ were chosen to mimic environmental bloom decline. Using the photosynthetic quantum yield $(\mathrm{Fv} / \mathrm{Fm})$ as a proxy for overall diatom health [8], after 


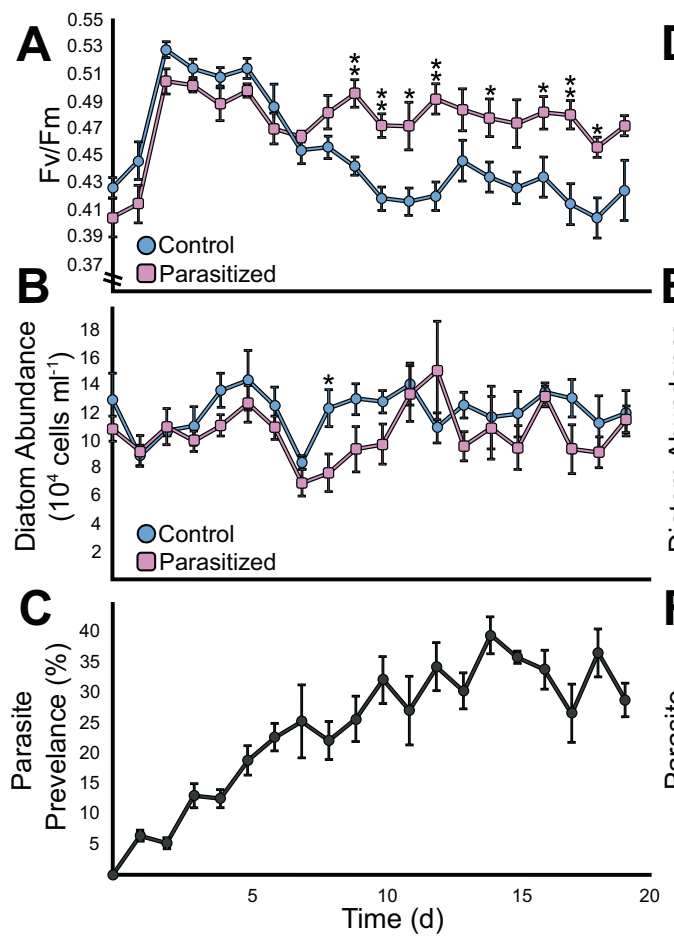

Fig. 2 Selective targeting of unhealthy diatom cells by thraustochytrids improves the overall health of the diatom population. A-C Population dynamics of the Fv/Fm (A) and total number (B) of stationary Chaetoceros diatoms for control and parasitized diatom populations over the experimental period $( \pm \mathrm{SEM}, n=5)$. Welch's ttest $* p<0.05, * * p<0.01, * * * p<0.001$. The parasite prevalence did not exceed about a third of the total population $(\mathbf{C})( \pm$ SEM, $n=5)$. Parasites added at $0 \mathrm{~d}$. In a separate experiment (D-F), a clonal Chaetoceros population was generated. Population dynamics of the

$8 \mathrm{~d}$, the parasitized Chaetoceros sp. populations were consistently healthier than those in the control non-exposed populations (Fig. 2A). Diatom population density was similar in both treatments (Fig. 2B) and parasite prevalence peaked after 8 days (Fig. 2C). In a separate experiment to investigate the role of genotype specificity in ThrauL4 parasitism, we generated a clonal Chaetoceros sp. population by single-cell picking and exposed the population to ThrauL4 cultures growing independently from diatoms. Although the clonal population declined in health more rapidly overall, ThrauL4 parasitism also resulted in healthier populations (Fig. 2D-F) suggesting that these results are a not an artefact of genotype specificity and succession.

By removing physiologically weaker individuals from the population, the remaining cells will constitute an overall healthier population. However, other mechanisms may also promote an overall healthier diatom population. It may be that selective parasitism relieves nutrient competition between unhealthy and healthy individuals. In the natural environment, diatom-diatom competition is a major growth limiting factor $[9,10]$ and removing the pressure exerted by weaker cells may allow the population to be more robust. It is also possible that the thraustochytrid could be 'cleaning' the population by preventing the build-up of toxic waste products or the proliferation of detrimental co-culture bacteria in an analogous way to how carrion removal by vultures prevents the spread of diseases to mammals [11]. In addition, thraustochytid parasitism could accelerate nutrient recycling by releasing nutrients from dying cells. The consequences of physiology-selective diatom parasitism should be assessed in the marine environment, including impacts at the community scale and in the context of ecosystem functioning.

The proposed influence of thraustochytrid parasitism on diatom population health is summarised in Fig. 2G. We suggest that this thraustochytrid-diatom interaction provides evidence of 'healthy herd' dynamics in a protist-protist interaction, an ecological phenomenon typically associated with animal predator-prey interactions [3]. As we show here with ThrauL4, animal predators such as lions [12], cougars [13], African wild dogs [14], and wolves [15] have been shown to target prey with suboptimal health. The 'healthy herd' hypothesis states that by selective predation on unhealthy prey, 
predators increase the overall health of the prey population by increasing resource availability or by removing potential carriers of disease [3]. Evidence for 'healthy herd' dynamics where predation generates healthier prey populations has also been demonstrated in lobster-sea urchin [16], fish-Daphnia [17], and fox-grouse [18] predator-prey systems. Here, we provide analogous supportive evidence from a marine protist-protist system.

'Heathy herd' dynamics between protists challenges the assumption that protist-protist parasitism is always detrimental to the host population and raises caution in this assumption in ecosystem modelling or inference from molecular ecology surveys (e.g., metabarcoding). Our results have demonstrated the potential complexity of protist-protist symbioses, highlighting the value of culturebased experimentation and the importance of developing model co-culture systems in resolving complex ecological interactions. The underpinning biology and ecological importance in natura of such interactions now require further investigation.

Acknowledgements We thank the crew of the RV Sepia for sampling and Angela Ward and Claire Hopkins (MBA) for their guidance with isolation and culturing. We also thank Glenn Harper, Alex Strachan and the team at the Plymouth Electron Microscopy Centre (PEMC) for their assistance with SEM. We are indebted to Jingwen Pan (University of British Columbia) and Javier del Campo (Institute of Evolutionary Biology, Spain) for providing the reference sequences used in building phylogenetic trees in this study, as well as to Daniel Vaulot (Station Biologique de Roscoff) for help in interpreting the Ocean Sampling Day data. Nathan Chrismas (MBA) is also thanked for bioinformatic support.

\section{Compliance with ethical standards}

Conflict of interest The author declares no competing interests.

Publisher's note Springer Nature remains neutral with regard to jurisdictional claims in published maps and institutional affiliations.

\section{References}

1. Slobodkin LB. Prudent predation does not require group selection. Am Nat. 1974;108:665-78.
2. Williams PD. Unhealthy herds: some epidemiological consequences of host heterogeneity in predator-host-parasite systems. J Theor Biol. 2008;253:500-7.

3. Packer C, Holt RD, Hudson PJ, Lafferty KD, Dobson AP. Keeping the herds healthy and alert: Implications of predator control for infectious disease. Ecol Lett. 2003;6:797-802.

4. Lima-Mendez G, Faust K, Henry N, Decelle J, Colin S, Carcillo F, et al. Determinants of community structure in the global plankton interactome. Science 2015;348:1262073.

5. Skovgaard A. Dirty tricks in the plankton: Diversity and role of marine parasitic protists. Acta Protozool. 2014;53:51-62.

6. Jephcott TG, Sime-Ngando T, Gleason FH, Macarthur DJ. Hostparasite interactions in food webs: Diversity, stability, and coevolution. Food Webs. 2016;6:1-8.

7. Nelson DM, Tréguer P, Brzezinski MA, Leynaert A, Quéguiner B. Production and dissolution of biogenic silica in the ocean: Revised global estimates, comparison with regional data and relationship to biogenic sedimentation. Glob Biogeochem Cycles. 1995;9:359-72.

8. Timmermans KR, Veldhuis MJ, Brussaard CP. Cell death in three marine diatom species in response to different irradiance levels, silicate, or iron concentrations. Aquat Micro Ecol. 2007;46:253-61.

9. Pinto E, Van Nieuwerburgh L, De Barros MP, Pedersén M, Colepicolo P, Snoeijs P. Density-dependent patterns of thiamine and pigment production in the diatom Nitzschia microcephala. Phytochemistry. 2003;63:155-63.

10. Manoylov KM. Intra- and interspecific competition for nutrients and light in diatom cultures. J Freshw Ecol. 2009;24:145-57.

11. Houston DC, Cooper JE. The digestive tract of the whiteback griffon vulture and its role in disease transmission among wild ungulates. J Wildl Dis. 1975;11:306-13.

12. Schaller G. The Serengeti lion: a study of predator-prey relations. London: University of Chicago Press; 1972.

13. Krumm CE, Conner MM, Hobbs NT, Hunter DO, Miller MW. Mountain lions prey selectively on prion-infected mule deer. Biol Lett. 2010;6:209-11.

14. Pole A, Gordon IJ, Gorman ML, MacAskill M. Prey selection by African wild dogs (Lycaon pictus) in southern Zimbabwe. J Zool. 2004;262:207-15.

15. Husseman JS, Murray DL, Power G, Mack C, Wenger CR, Quigley H. Assessing differential prey selection patterns between two sympatric large carnivores. Oikos. 2003;101:591-601.

16. Lafferty KD. Fishing for lobsters indirectly increases epidemics in sea urchins. Ecol Appl. 2004;14:1566-73.

17. Duffy MA, Hall SR, Tessier AJ, Huebner M. Selective predators and their parasitized prey: Are epidemics in zooplankton under top-down control? Limnol Oceanogr. 2005;50:412-20.

18. Hudson PJ, Dobson AP, Newborn D. Do parasites make prey vulnerable to predation? Red grouse and parasites. J Anim Ecol. 1992;61:681. 